\title{
INTERALLELIC RECOMBINATION AT THE his-5 LOCUS IN NEUROSPORA CRASSA
}

\author{
BRIAN R. SMITH * \\ Department of Genetics, Australian National University, Canberra, A.C.T., Australia
}

\section{INTRODUCTION}

Received 2 1.xi.64

The histidine-5 gene of Neurospora crassa is situated in the right arm of chromosome IV between pyrimidine-3 and tryptophan-4 (Smith, I962). The gene apparently controls the primary structure of the enzyme glutamate-phosphohistidinol transaminase which catalyses the conversion of imidazole acetol phosphate to L-histidinol phosphate (Ames and Horecker, I956).

A considerable number of his-5 auxotrophic mutants are known some of which exhibit complementation. The complementation matrix of 60 his- 5 mutants was interpreted in a linear complementation map within which eight distinct complementing groups were apparent (Catcheside, 1960). Study of the complementation characteristics of these 60 his- 5 alleles and a further 30 has revealed only slight changes in this complementation map (p. 271). The complementation map is not so simple, nor the number of alleles so few that an exact colinearity between genetic and complementation maps might be expected by chance, and to test this possibility was the main reason for attempting to map the fine structure of his-5.

Mapping of the sites of difference in the gene depends primarily on the frequencies of prototrophs found amongst ascospores produced by crosses between pairs of auxotrophs in the repulsion phase. This assumes that the frequency of prototrophs found in such crosses is a measure of the physical distance between the sites at which the two auxotrophs differ from one another. Thus any pair of auxotrophic alleles, $m^{1}$ and $m^{2}$, would show a frequency which was the sum or the difference of the frequencies shown by crosses of these alleles with a third auxotroph. If this additivity rule held, it should be possible to arrange the sites of mutation in an unambiguous order.

In this work, mapping was not solely dependent upon prototroph frequency, but also on the distribution of the combinations of flanking markers amongst the prototrophs produced by crosses. In a cross of the general type $A m^{1} B \times a m^{2} b$ where $A$ and $a$ are the proximal and $B$ and $b$ are the distal flanking markers, the prototrophs, $m^{+}$fall into four classes. These are the two parental combinations $A B$ and $a b$ and

* Work largely done in Department of Microbiology, University of Birmingham, while holder of a D.S.I.R. Research Studentship.

$\mathrm{R}$ 
the two recombinants $A b$ and $a B$. In Neurospora no one recombinant class vastly exceeds any other class and all four occur with substantial frequencies. However, some asymmetries are observed. The recombinant classes are often unequal in size. The parental classes are often unequal in size, and the directions of inequality of the parental and recombinant classes are correlated. It has often been assumed that the inequalities are due to "normal " crossing-over and that the high frequencies of parental and the second recombinant classes are due to the simultaneous occurrence of two or three crossovers indicating a high degree of "negative interference". However, high negative interference has been invoked merely as a description of the factor which is necessary to fit the observations to the crossover theory
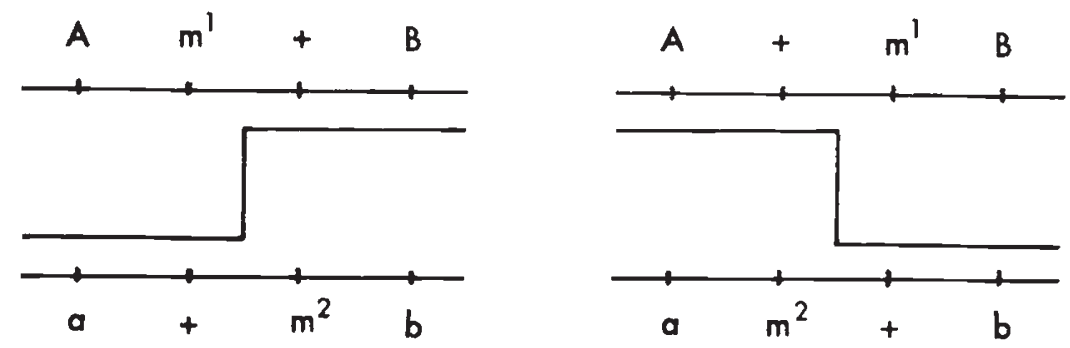

FIs. 1.-Diagram to show the derivation of the criteria for ordering the sites of difference $m^{2}$ and $m^{2}$ based on the distribution of flanking markers $A$ and $B$ amongst prototrophic

of recombination. The main concern of this paper is not so much with the theory of recombination as with the ways in which the data may be used to order the sites of mutation.

The relationships used to indicate the order of the sites of mutation are best understood if it is assumed that recombination does occur by a process analogous to crossing-over. Three criteria may be considered.

I. If the recombinant classes are compared, the order will be $A m^{1} m^{2} B$ if $a B$ is in the majority and will be $A m^{2} m^{1} B$ if $A b$ is in the majority (see fig. I).

2. If the proximal flanking alleles only are considered, the order ivill be $A m^{1} m^{2}$ if $a$ is in the majority and will be $A m^{2} m^{1}$ if $A$ is in the majority. In other words, the more frequent proximal flanking allele identifics the more distal of the $m$ allele differences since they entered the cross together.

3. If the distal flanking alleles are considered, the order will be $m^{1} m^{2} B$ if $B$ is in the majority and will be $m^{2} m^{1} B$ if $b$ is in the majority. That is, the more frequent distal flanking allele identifies the more proximal of the $m$ allele differences since they entered the cross together.

The first criterion uses only the recombinant classes, whereas the second and third criteria also use the parental classes. Hence although the second and third criteria are not wholly independent of the first, they do have the merit of using all the progeny scored. 
If any, or all, of these criteria lead to the derivation of a consistent order for a series of alleles, this order must be considered as meaningful. Consistency may be expected to hold between a series of pairs of a set of alleles considered with respect to one critcrion and bctween the three criteria applied to one pair of alleles. Inconsistency can only be considered significant if the order inferred is based on a significant difference in frequency between the classes of prototrophs compared.

\section{MATERIALS AND METHODS}

\section{(a) Organisms}

The his-5 mutants comprise 90 alleles, 88 of which werc isolated by Catcheside from Emerson $a$ by filtration enrichment following irradiation with ultra-violet light.

TABLE 1

Histidine- 5 alleles and their complementation groups

\begin{tabular}{|c|c|c|}
\hline $\begin{array}{l}\text { Complementation } \\
\text { group }\end{array}$ & $\begin{array}{l}\text { Number of alleles } \\
\text { in each group }\end{array}$ & Mutant isolation number \\
\hline $\begin{array}{l}\text { B } \\
\mathrm{C} \\
\mathrm{D} \\
\mathrm{E} \\
\mathrm{F} \\
\mathbf{G}\end{array}$ & $\begin{array}{r}2 \\
1 \\
10 \\
7 \\
4 \\
17 \\
1 \\
4 \\
\frac{1}{4}\end{array}$ & 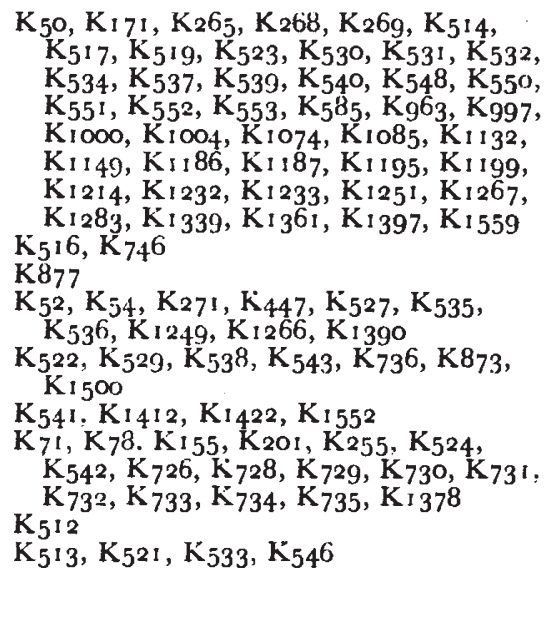 \\
\hline
\end{tabular}

The remaining two, $\mathrm{K} 873$ and $\mathrm{K} 877$, were isolated by the author after irradiation of the same wild type with gamma rays. The his-5 mutants are listed in table : The pyrimidine- 3 mutant used was 1298 originally received from Dr G. W. Beadle. The leucine-2 mutant $3750 \mathrm{I}$ was kindly donated by $\mathrm{Dr} \mathrm{D}$. D. Perkins. Pyr-3 is about one map unit proximal to his-5 and leu-2 about nine map units distal to his-5.

\section{(b) Media}

All stocks were grown and kept on slopes of Vogel's medium (Vogel, 1955), suitably supplemented. Crosses were made on slopes of Westergaard's medium (Westergaard and Mitchell, 1947) containing folded strips of filter paper. Cultures were tested for biochemical requirements on Vogel's medium in which 0.5 per cent. sorbose and $0 \cdot 1$ per cent. sucrose replaced the usual 2 per cent. sucrose. Supplements of growth factors were added to these media where necessary, to give the 
following concentrations; for histidine mutants, $300 \mathrm{mg} . / \mathrm{l}$, of L-histidine monohydrochloride, for the pyr-3 mutant $500 \mathrm{mg}$. $/ 1$ of uracil and for the leu-2 mutant $600 \mathrm{mg} . / \mathrm{l}$. of DL-leucine.

\section{(c) Crosses}

Each cross for analysis of prototroph frequency was made in seven to twenty tubes of crossing medium and ascospores from the different tubes were pooled. The: ascospores were collected in sterile water, filtered through muslin, and after removal of excess water by decantation suspended in 0.1 per cent. agar. 'The number of' spores per ml. of suspension was estimated by counting the number in $0.01 \mathrm{ml}$. drops of suspension on slides on which the area covered by the coverslip was divided into sixty-four squares. The ascospores were screened for prototrophs by a modification of the layer plating technique (Newmeyer, r954; Murray, I960). Germination of the ascospores suspended in $0 \cdot 1$ per cent. agar was induced by heat treatment at $5^{\circ} \mathrm{C}$. for 60 minutes. Known volumes of spore suspension were then pipetted into tubes containing $2.5 \mathrm{ml}$. volumes of 0.5 per cent. agar supplemented with uracil and leucine which was kept molten at $45^{\circ} \mathrm{C}$. The contents of each tube werc quickly mixed and evenly spread on plates of Vogel's medium supplenented with uracil and leucine. The plates were then incubated at $25^{\circ} \mathrm{C}$. and scanned under a stereomicroscope after 18 hours, 42 hours and 66 hours. Prototrophs were transferred to slopes of Vogel's medium containing uracil and leucine and later classified for pyr-3 and leu-2. The viability of the ascospores of each cross was estimated in samples layer plated on Vogel's medium plus histidine, uracil and leucine.

\section{RESULTS}

Crosses of the type pyr-3 his $-5^{x}+\mathrm{X}+$ his $-5^{y}$ leu-2 were prepared, where his $-5^{x}$ and his $-5^{y}$ designate two his -5 alleles and pyr-3 (1 298) and leu-2 (3750I) are proximal and distal markers respectively. Spores from such crosses were analysed for their frequency of prototroph formation. The prototrophs were then classified for the four combinations of flanking markers, the two parental pyr-3 + and +leu-2, and the two recombinant, ++ and pyr-3 letl-2. The data are summarised in table 2. The important statistics in this table are (i) the frequencies of prototrophs per hundred thousand ascospores analysed in a cross and (ii) the order of the his-5 allele differences as deduced from the distribution of the four classes of flanking marker combinations amongst these prototrophs. These two aspects of the data are considered separately.

\section{(a) Prototroph frequencies}

The observed frequencies of prototrophs ranged from zero to 35 or so per $10^{5}$ ascospores. Of eight self crosses, crosses 1 to 8 in table 2, only one yielded any prototrophs. This was the self cross $\mathrm{K}_{550} \times \mathrm{K}_{550^{*}}$ which yielded one prototroph in $18.6 \times 10^{5}$ ascospores. This was taken to indicate a higher reversion rate of $\mathrm{K}_{550}$ than is usual for most his- 5 mutants. We shall see $(p, 226)$ that this is so.

The data include twelve sets of two or more crosses between

* In writing the constitution, only the allele numbers of the his-5 mutants will be given. Strictly the constitution here should be his-5 $\mathrm{K}_{550}$. 
particular pairs of alleles where the stocks were reciprocally or independently marked. These sets of families are bracketed in table 2 . In three of these sets, the frequency of prototroph formation in reciprocally marked crosses did not differ significantly. These were

TABIE 2

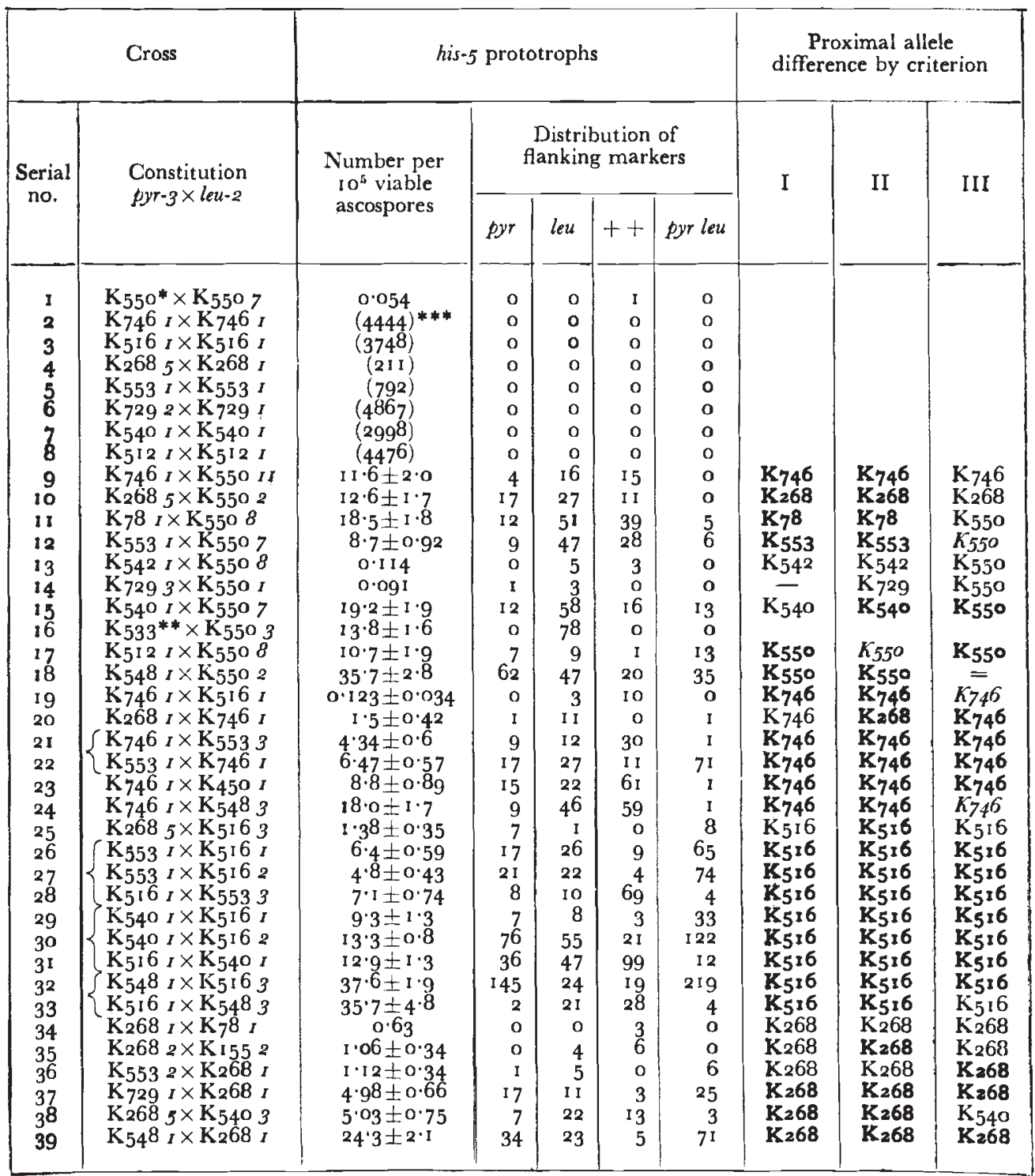

families 32 and 33,40 and 41 and 63 and 64 . In the other nine sets, frequencies of prototroph formation differed significantly between families. In no case was the highest frequency more than double the lowest frequency for crosses between the same pair of alleles. The 
greatest difference was between families 29 and 31 for croşses between the reciprocally marked his-5 alleles $\mathrm{K}_{540}$ and $\mathrm{K}_{51} 6$, which gave frequencies of $9.3 \pm 1 \cdot 3$ and $17 \cdot 9 \pm 1 \cdot 3$ respectively. The difference, $8.6 \pm 1.8$ is highly significant $(\mathrm{P}<0.000,0 \mathrm{I})$.

Within each of the 12 sets of families the relative distribution of the prototrophs amongst the four marker classes did not vary significantly. This indicates that the variations in frequencies do

TABLE 2-(continued)

\begin{tabular}{|c|c|c|c|c|c|c|c|c|c|}
\hline & Cross & & prot & & & & diffe & $\begin{array}{l}\text { ximal } \\
\text { nce by }\end{array}$ & $\begin{array}{l}\text { le } \\
\text { terion }\end{array}$ \\
\hline Serial & Constitution & & & $\begin{array}{l}\text { Distri } \\
\text { ankin }\end{array}$ & $\begin{array}{l}\text { oution } \\
\text { g mar }\end{array}$ & & & & \\
\hline & & & pyr & leu & ++ & pyr leu & & & \\
\hline 40 & $\mathrm{~K}_{7} 8_{l} \mathrm{~K}_{155} t$ & $(4619)$ & 0 & o & 0 & 0 & & & \\
\hline 41 & $\left\{\mathrm{~K}_{155}{ }_{t \times \mathrm{K}_{78}}\right.$ & $(1815)$ & 0 & o & 0 & 0 & & & \\
\hline 42 & $\mathrm{~K}_{553} t \times \mathrm{K}_{78} \mathrm{I}$ & $1.82 \pm 0.29$ & 9 & 7 & 6 & 17 & $\mathbf{K}_{78}$ & $K_{78}$ & $K_{7} 8$ \\
\hline 43 & $\int \mathbf{K}_{78} t \times \mathbf{K}_{729} t$ & $5.01 \pm 0.59$ & II & $1 i$ & 48 & 2 & $\mathbf{K}_{78}$ & $\mathbf{k}_{78}$ & $\mathbf{K}_{78}$ \\
\hline 44 & $\left\{\mathrm{~K}_{729} \times \mathrm{K}_{78}\right.$ & $2 \cdot 78 \pm 0.22$ & 27 & 27 & 8 & 92 & $\mathbf{K}_{78}$ & $\mathbf{K}_{78}$ & $\mathbf{K}_{78}$ \\
\hline 45 & $\mathrm{~K}_{78} 1 \times \mathrm{K}_{540_{2}}$ & $8.35 \pm 0.96$ & 17 & 23 & 29 & 6 & $\mathbf{K}_{78}$ & $\mathbf{K}_{78}$ & $\mathbf{K}_{78}$ \\
\hline 46 & $\mathbf{K}_{540_{I} \times \mathbf{K}_{78} t}$ & $4.65 \pm 0.75$ & 8 & 7 & I & 23 & $\mathbf{K}_{78}$ & $\mathbf{K}_{78}$ & $\mathbf{K}_{78}$ \\
\hline $\begin{array}{l}40 \\
47\end{array}$ & $\mathrm{~K}_{78} t \times \mathrm{K}_{548} t$ & $30.5 \pm 4.0$ & 7 & 23 & 27 & $\begin{array}{r}23 \\
2\end{array}$ & $\begin{array}{l}\mathbf{K}_{78}^{\circ} \\
\mathbf{K}_{7}\end{array}$ & $\begin{array}{l}\mathbf{K}_{78} \\
\end{array}$ & $\kappa 78$ \\
\hline 48 & $\mathrm{~K}_{553} I \times \mathrm{K}_{155}$ & $1.74 \pm 0.44$ & 3 & 4 & 1 & 8 & $\mathrm{~K}_{155}$ & $K_{155}$ & $K_{155}$ \\
\hline 49 & $\mathrm{~K}_{542} t \times \mathrm{K}_{155}$ & $2 \cdot 1 \pm 0.25$ & 17 & I 1 & 3 & 40 & $\mathrm{~K} \times 55$ & $K_{155}$ & $K_{155}$ \\
\hline 50 & $\mathrm{~K}_{729} \times \mathrm{K}_{155}$ & $2 \cdot 16 \pm 0 \cdot 27$ & 16 & 7 & 2 & 40 & $\mathbf{K}_{\mathbf{I}}$ & KI55 & $K \times 55$ \\
\hline $5^{1}$ & $\mathrm{~K}_{540} \mathrm{I} \times \mathrm{K}_{155} \mathrm{I}$ & $3.33 \pm 0.56$ & 3 & 17 & o & 15 & $\mathbf{K}_{\mathbf{I}}$ & $\mathbf{K}_{1}$ & $\mathrm{~K}_{\mathbf{I}}$ \\
\hline 52 & $\mathrm{~K}_{155 l} 1 \times \mathrm{K}_{548}{ }_{3}$ & $23 \cdot 3 \pm 4 \cdot 76$ & 2 & 6 & 16 & 0 & $\mathbf{K}$ & $\mathbf{K}_{\mathbf{I}}$ & $\mathbf{K}_{\mathbf{I}}$ \\
\hline 53 & $\mathrm{~K}_{553 t \times \mathrm{K}_{542 t}}$ & $1.54 \pm 0.4$ & o & 7 & 8 & 0 & $\mathrm{~K}_{5}$ & $\mathbf{K}_{5}$ & $K_{553}$ \\
\hline 54 & $\mathrm{~K}_{553} \mathrm{t} \times \mathrm{K}_{729 t}$ & $1.22 \pm 0.29$ & 1 & 5 & 12 & 0 & $\mathbf{K}_{5}$ & & $\kappa_{5}$ \\
\hline 55 & $\left(\mathrm{~K}_{553} \mathrm{I} \times \mathrm{K}_{540 \mathrm{I}}\right.$ & $3.8 \pm 0.26$ & 25 & 70 & 83 & 25 & $\mathbf{k}_{5}$ & $\mathbf{K}_{5}$ & $\mathrm{~K}_{553}$ \\
\hline 56 & $\left\{\mathrm{~K}_{540} 1 \times \mathrm{K}_{5533}\right.$ & $2 \cdot 2 \pm 0.18$ & $3^{8}$ & 22 & 15 & 63 & $\mathbf{K}_{5}$ & $\mathbf{K}_{5}$ & $\mathbf{K}_{553}$ \\
\hline 57 & $\left(\mathrm{~K}_{54}{ }_{1} I \times \mathrm{K}_{553} 4\right.$ & $2 \cdot 6 \pm 0 \cdot 25$ & 20 & $2 I$ & 6 & 61 & $\mathbf{k}_{5}$ & & $\mathbf{K}_{553}$ \\
\hline $5^{8}$ & $\mathrm{~K}_{553} \mathrm{I} \times \mathrm{K}$ & $5 \cdot 6 \pm 0 \cdot 82$ & 5 & 17 & 15 & 9 & & & \\
\hline 59 & $\mathrm{~K}_{553} 1 \times \mathrm{K}_{5121}$ & $3.85 \pm 0.59$ & 4 & 12 & 27 & 0 & $\mathbf{K}_{5}$ & $\mathbf{K}_{5}$ & $\mathbf{K}_{5}$ \\
\hline 60 & $\left(\mathrm{~K}_{548}{ }_{1} \times \mathrm{K}_{553}{ }_{2}\right.$ & $13 \cdot 1 \pm 1 \cdot 0$ & 74 & 13 & 5 & 65 & $\mathbf{K}_{5}$ & $\mathbf{K}_{5}$ & $\mathrm{~K}_{548}$ \\
\hline $6 \mathrm{I}$ & $\left\{\mathrm{K}_{553} t \times \mathrm{K}_{548} t\right.$ & $16 \cdot 2 \pm 1 \cdot 26$ & 14 & 62 & $7 \breve{6}$ & 13 & $\mathbf{K}_{553}$ & $\mathbf{K}_{553}$ & $\kappa_{553}$ \\
\hline 62 & $\mathrm{~K}_{553} I \times \mathrm{K}_{548}{ }_{3}$ & $x 6.0 \pm 1 \cdot 2$ & 19 & 59 & 83 & 17 & $\mathrm{~K}_{553}$ & $\mathrm{~K}_{553}$ & $K_{553}$ \\
\hline 63 & $\left\{\mathrm{~K}_{542}{ }_{1 \times \mathrm{K}_{729} \mathrm{I}}\right.$ & $(2771)$ & 0 & 0 & 0 & o & - & & \\
\hline 64 & $\left\{\mathrm{~K}_{729} 1 \times \mathrm{K}_{5422}\right.$ & 0.028 & 2 & 0 & o & o & - & $\mathrm{K}_{542}$ & $\mathrm{~K}_{729}$ \\
\hline 65 & $\mathrm{~K}_{540 I \times \mathrm{K}_{542} \mathrm{I}}$ & $0.6 \mathrm{r}$ & 2 & 2 & 0 & 1 & $\mathrm{~K}_{542}$ & & $\mathrm{~K}_{542}$ \\
\hline 66 & $\mathrm{~K}_{54{ }^{2} I} x \mathrm{~K}_{548} \mathrm{I}$ & $8 \cdot 43 \pm 1 \cdot 8$ & 4 & 8 & 9 & $i$ & $\mathbf{K}_{542}$ & $\mathbf{k}_{542}$ & $\mathrm{~K}_{542}$ \\
\hline 67 & $\mathrm{~K}_{540} x \times \mathrm{K}_{729} \mathrm{I}$ & $0.49 \pm 0.13$ & $\stackrel{+}{0}$ & 2 & 3 & 9 & $K_{729}$ & $K_{729}$ & $\mathbf{K} 729$ \\
\hline 68 & $\mathrm{~K}_{540} t \times \mathrm{K}_{553}$ & $2.25 \pm 0.49$ & 3 & 7 & 7 & 4 & $\mathrm{~K}_{540}$ & $K_{540}$ & $\mathbf{K}_{533}$ \\
\hline 69 & $\int \mathrm{K}_{5401 \times \mathrm{K}_{5121}}$ & $3.5 \pm 0.5$ & II & 23 & 12 & 4 & $\mathbf{K}_{540}$ & $\mathbf{K}_{540}$ & $\mathrm{~K}_{512}$ \\
\hline 70 & $\mathrm{~K}_{5123} \times \mathrm{K}_{540_{2}}$ & $6.17 \pm 0.64$ & (94 & not tes & ted) & & & & \\
\hline 71 & $\left\{\mathbf{K}_{540} x \times \mathrm{K}_{548 I}\right.$ & $14.9 \pm 0.67$ & 81 & 216 & 146 & 45 & $\mathbf{K}_{540}$ & $\mathbf{K}_{540}$ & $K_{548}$ \\
\hline 72 & $\mathrm{~K}_{54}{ }^{2} \mathrm{l} \times \mathrm{K}_{54} \mathrm{O}_{3}$ & $9.9 \pm 1 \cdot 1$ & 35 & 18 & 7 & 22 & $\mathrm{~K}_{540}$ & $\mathbf{K}_{540}$ & $\mathbf{K}_{548}$ \\
\hline 73 & $\mathrm{~K}_{512}{ }_{1} \times \mathrm{K}_{533}$ & 0.031 & 0 & o & o & 2 & $\mathbf{K}_{533}$ & $\mathbf{K}_{533}$ & $\mathbf{K}_{533}$ \\
\hline 74 & $\mathrm{~K}_{5481 \times \mathrm{K}_{533} 3}$ & $2 \cdot 74 \pm 0.41$ & 17 & 6 & 2 & 20 & $\mathbf{K}_{533}$ & $\mathrm{~K}_{533}$ & $K_{533}$ \\
\hline 75 & $\mathrm{~K}_{5121} \times \mathrm{K}_{54^{8} 2}$ & $3.69 \pm 0.85$ & 4 & 5 & 7 & 3 & $K_{512}$ & $K_{512}$ & $\mathrm{~K}_{512}$ \\
\hline
\end{tabular}

* This component did not contain any marker mutant.

* This component contained the leu-2 marker mutant 37501 .

*** In crosses where no prototrophs were found the number of viable ascospores screened in thousands is given in brackets. For each cross the total number of prototrophs obtained may be found by adding the four classes of prototrophs. 
not result from differences in the viability of the four marker combinations. It seems probable that the differences between these families has a genetic basis.

When considering theories of recombination it is necessary to know whether factors which affect allelic recombination also affect inter-genic recombination. Consequently, experiments were made to measure the frequency of recombination between flanking marker genes in the general populations of some of those sets of crosses exhibiting significantly different frequencies of histidine prototrophs.

(i) Frequency of allelic recombination and its relation to recombination between marker genes. Estimates of the rate of recombination between flanking markers in the general population of a number of crosses were obtained in two ways. In the first, suspensions of ascospores were plated on Vogel's medium supplemented with histidine, uracil and leucine and resulting colonies were classified for their marker constitution. The second was a selective method in which suspensions of ascospores were plated on Vogel's medium supplemented with histidine. Only the recombinant class that is prototrophic with respect to the outside markers is able to grow on this medium. An estimate of the viability of the spores was obtained by plating on Vogel's medium containing histidine, uracil and leucine. The frequency of prototrophic recombinants was then determined and doubled togive the frequency of recombination between the marker genes.

Using the selective method, values for the frequency of recombination between flanking markers were obtained for three crosses between $\mathrm{K}_{540}$ and $\mathrm{K}_{516}$, three between $\mathrm{K}_{540}$ and $\mathrm{K}_{553}$, two between $\mathrm{K}_{548}$ and $\mathrm{K}_{553}$ and two between $\mathrm{K}_{553}$ and $\mathrm{K}_{51}{ }^{16}$. The results are tabulated in table 3 which shows the limits to the frequency of recombination between the flanking markers and also the limits to the frequency of histidine prototroph formation when $\mathrm{P}=0.05$. Values for recombination between flanking markers using the non-selective method were obtained for two of the three crosses between the his-5 alleles $\mathrm{K}_{540}$ and $\mathrm{K}_{51} 6$ and are shown in table 4. These values are almost identical to those observed for the same crosses using the selective method. The data in table 4 also indicate that the recombinant classes occur with equalfrequency as is expected in crosses between genes.

In order to show that the differences in the frequencies of histidine prototroph formation and recombination between flanking markers are not the result of variations in environmental conditions that might affect recombination, two of the crosses between $\mathrm{K}_{540}$ and $\mathrm{K}_{51} 6$ were set up again after a considerable interval and fresh estimates for the frequencies obtained. The results of the repeated crosses are shown in table 3 , serial numbers $29 \mathrm{~b}$ and $3 \mathrm{Ib}$. It is apparent that the estimates from the repeated crosses do not differ significantly from the original estimates and it therefore seems highly probable that the variations of the various frequencies in the independently or reciprocally marked crosses are genetic in origin. 
Inspection of the data in table 3 reveals a correlation between frequency of histidine prototroph formation and frequency of recombination between flanking markers. The relationship is best understood if the results are shown graphically. Fig. 2 shows the frequency

TABLE 3

Showing per cent. recombination between proximal and distal markers and frequency of histidine prototroph formation. Limits to the frequencies are shown where $P=0.05$. The isolate number of the components of each cross immediately succeed the mating type

\begin{tabular}{|c|c|c|c|c|c|c|c|}
\hline \multicolumn{2}{|r|}{ Cross } & \multirow{2}{*}{$\begin{array}{l}\text { Total } \\
\text { germination }\end{array}$} & \multirow{2}{*}{$\begin{array}{l}\text { No. of } \\
\text { this }+ \\
\text { colonies }\end{array}$} & \multirow{2}{*}{$\begin{array}{l}\text { Per cent. } \\
\text { recombination } \\
\text { between pyr-3 } \\
\text { and leu-2 }\end{array}$} & \multicolumn{3}{|c|}{$\begin{array}{l}\text { Frequency of histidine } \\
\text { prototrophs per } 10^{5} \\
\text { ascospores }\end{array}$} \\
\hline $\begin{array}{c}\text { Serial } \\
\text { no. }\end{array}$ & $\begin{array}{c}\text { Marker constitution } \\
\text { pyr-3 } \times \text { leu-2 }\end{array}$ & & & & & $\begin{array}{c}\text { Upper } \\
\text { limit } \\
\mathbf{P}=0.05\end{array}$ & $\begin{array}{c}\text { Lower } \\
\operatorname{limit} \\
P=0.05\end{array}$ \\
\hline $\begin{array}{l}29 \mathrm{a} \\
29 \mathrm{~b} \\
30 \\
31 \mathrm{a} \\
3 \mathrm{Ib}\end{array}$ & $\begin{array}{l}\mathrm{K}_{540} a_{I} \times \mathrm{K}_{51} 6 A_{I} \\
\mathrm{~K}_{540} a_{I} \times \mathrm{K}_{51} A_{I} \\
\mathrm{~K}_{540} a_{I} \times \mathrm{K}_{51} 6 A_{2} \\
\mathrm{~K}_{51} 6 a_{I} \times \mathrm{K}_{540} A_{I} \\
\mathrm{~K}_{51} 6 a_{I} \times \mathrm{K}_{540} A_{I}\end{array}$ & $\begin{array}{l}5247 \\
1533 \\
4968 \\
1681 \\
2195\end{array}$ & $\begin{array}{r}245 \\
66 \\
312 \\
156 \\
203\end{array}$ & $\begin{array}{l}9 \cdot 34 \pm 1 \cdot 14 \\
8 \cdot 61 \pm 2 \cdot 35 \\
12 \cdot 57 \pm 1 \cdot 35 \\
18 \cdot 56 \pm 2 \cdot 77 \\
18 \cdot 5 \pm 2 \cdot 54\end{array}$ & $\begin{array}{r}9 \cdot 3 \\
9 \cdot 6 \\
13 \cdot 3 \\
17 \cdot 9 \\
16 \cdot 5\end{array}$ & $\begin{array}{l}12 \cdot 1 \\
11 \cdot 6 \\
14 \cdot 9 \\
20 \cdot 5 \\
19 \cdot 7\end{array}$ & $\begin{array}{l}7 \cdot 14 \\
7 \cdot 9 \\
11 \cdot 8 \\
15 \cdot 6 \\
13 \cdot 7\end{array}$ \\
\hline $\begin{array}{l}56 \\
57 \\
55\end{array}$ & $\begin{array}{l}\mathrm{K}_{540} a_{I} \times \mathrm{K}_{553} A_{3} \\
\mathrm{~K}_{540} a_{I} \times \mathrm{K}_{553} A_{4} \\
\mathrm{~K}_{553} a_{I} \times \mathrm{K}_{540} A_{I}\end{array}$ & $\begin{array}{l}5450 \\
5255 \\
1959\end{array}$ & $\begin{array}{l}253 \\
302 \\
176\end{array}$ & $\begin{array}{r}9 \cdot 28 \pm 1 \cdot 12 \\
11 \cdot 49 \pm 1 \cdot 26 \\
17 \cdot 97 \pm 2 \cdot 53\end{array}$ & $\begin{array}{l}2 \cdot 2 \\
2 \cdot 6 \\
3 \cdot 8\end{array}$ & $\begin{array}{l}2 \cdot 53 \\
3 \cdot 09 \\
4 \cdot 33\end{array}$ & $\begin{array}{l}1 \cdot 83 \\
2 \cdot 14 \\
3 \cdot 31\end{array}$ \\
\hline $\begin{array}{l}27 \\
26\end{array}$ & $\begin{array}{l}\mathrm{K}_{553} a_{I I} \times \mathrm{K}_{51} 6 A_{2} \\
\mathrm{~K}_{553} a_{I} \times \mathrm{K}_{51} 6 A_{I}\end{array}$ & $\begin{array}{l}2676 \\
1213\end{array}$ & $\begin{array}{l}128 \\
103\end{array}$ & $\begin{array}{r}9 \cdot 57 \pm 1 \cdot 62 \\
16 \cdot 98 \pm 3 \cdot 14\end{array}$ & $\begin{array}{l}4 \cdot 8 \\
6 \cdot 4\end{array}$ & $\begin{array}{l}5 \cdot 6 \\
7 \cdot 6\end{array}$ & $\begin{array}{l}3.99 \\
5.37\end{array}$ \\
\hline $\begin{array}{l}60 \\
62\end{array}$ & $\begin{array}{c}\mathrm{K}_{548} A I \times \mathrm{K}_{553} a_{2} \\
\mathrm{~K}_{553 a I} \times \mathrm{K}_{548} A_{3}\end{array}$ & $\begin{array}{l}1669 \\
1349\end{array}$ & $\begin{array}{r}69 \\
120\end{array}$ & $\begin{array}{r}8 \cdot 27 \pm 1 \cdot 91 \\
17 \cdot 79 \pm 3 \cdot 04\end{array}$ & $\begin{array}{l}13 \cdot 1 \\
16 \cdot 0\end{array}$ & $\begin{array}{l}15.3 \\
18.4\end{array}$ & $\begin{array}{l}11 \cdot 3 \\
13.8\end{array}$ \\
\hline
\end{tabular}

TABLE 4

Showing recombination per cent. between pyr-3 and leu-2.

Limits to the frequencies are given where $P=0.05$

\begin{tabular}{|c|c|c|c|c|c|c|}
\hline \multicolumn{2}{|r|}{ Cross } & \multicolumn{4}{|c|}{ Genotypes of progeny } & \multirow{3}{*}{$\begin{array}{l}\text { Per cent. } \\
\text { recombination } \\
\text { between } \\
\text { pyr-3 and leu-2 }\end{array}$} \\
\hline \multirow{2}{*}{$\begin{array}{l}\text { Serial } \\
\text { no. }\end{array}$} & \multirow{2}{*}{$\begin{array}{l}\text { Marker constitution } \\
\text { pyr-3 } \times \text { leu-2 }\end{array}$} & \multicolumn{2}{|c|}{$\begin{array}{c}\text { Parental } \\
\text { combinations }\end{array}$} & \multicolumn{2}{|c|}{$\begin{array}{l}\text { Recombinant } \\
\text { combinations }\end{array}$} & \\
\hline & & pyr hist & this leu & + his + & pyr his leu & \\
\hline 29 & $\mathrm{~K}_{540} a_{I} \times \mathrm{K}_{51} 6 A_{I}$ & I 79 & 196 & 18 & 22 & $9 \cdot 64 \pm 2 \cdot 84$ \\
\hline $3^{1}$ & $\mathrm{~K}_{51} 6 a_{I} \times \mathrm{K}_{540} A I$ & 127 & I 26 & 28 & 28 & $18 \cdot 12 \pm 4 \cdot 3$ \\
\hline
\end{tabular}



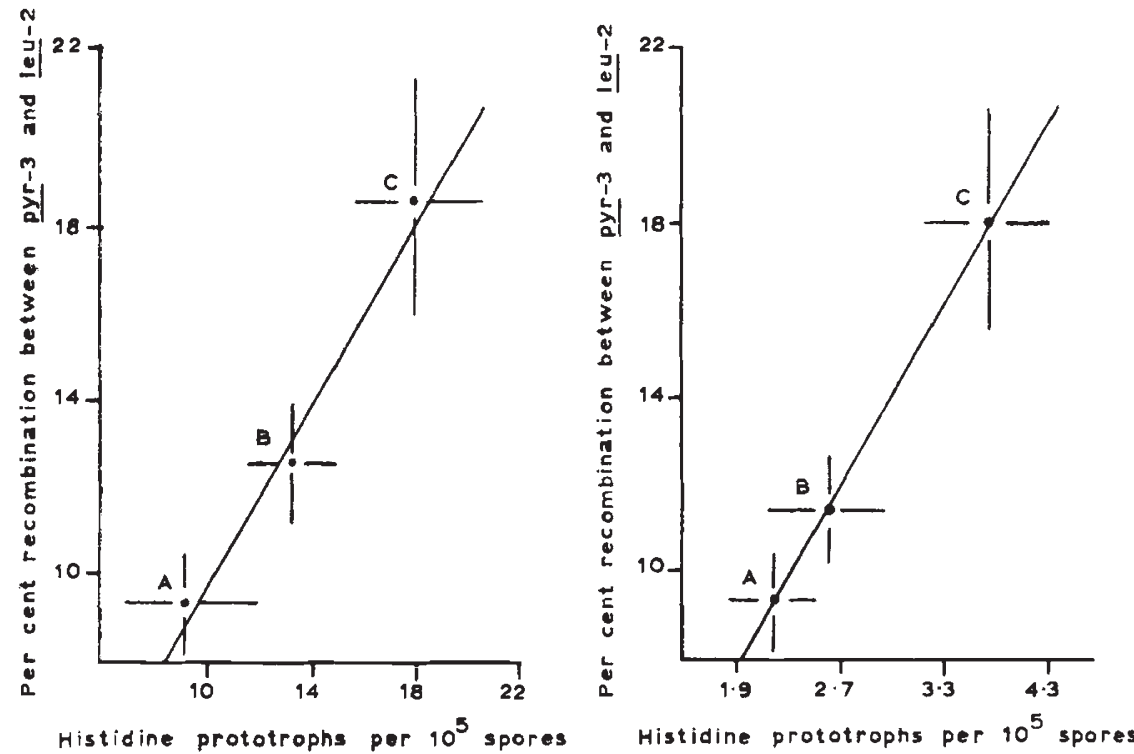

(a)

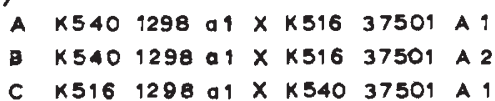

(b)
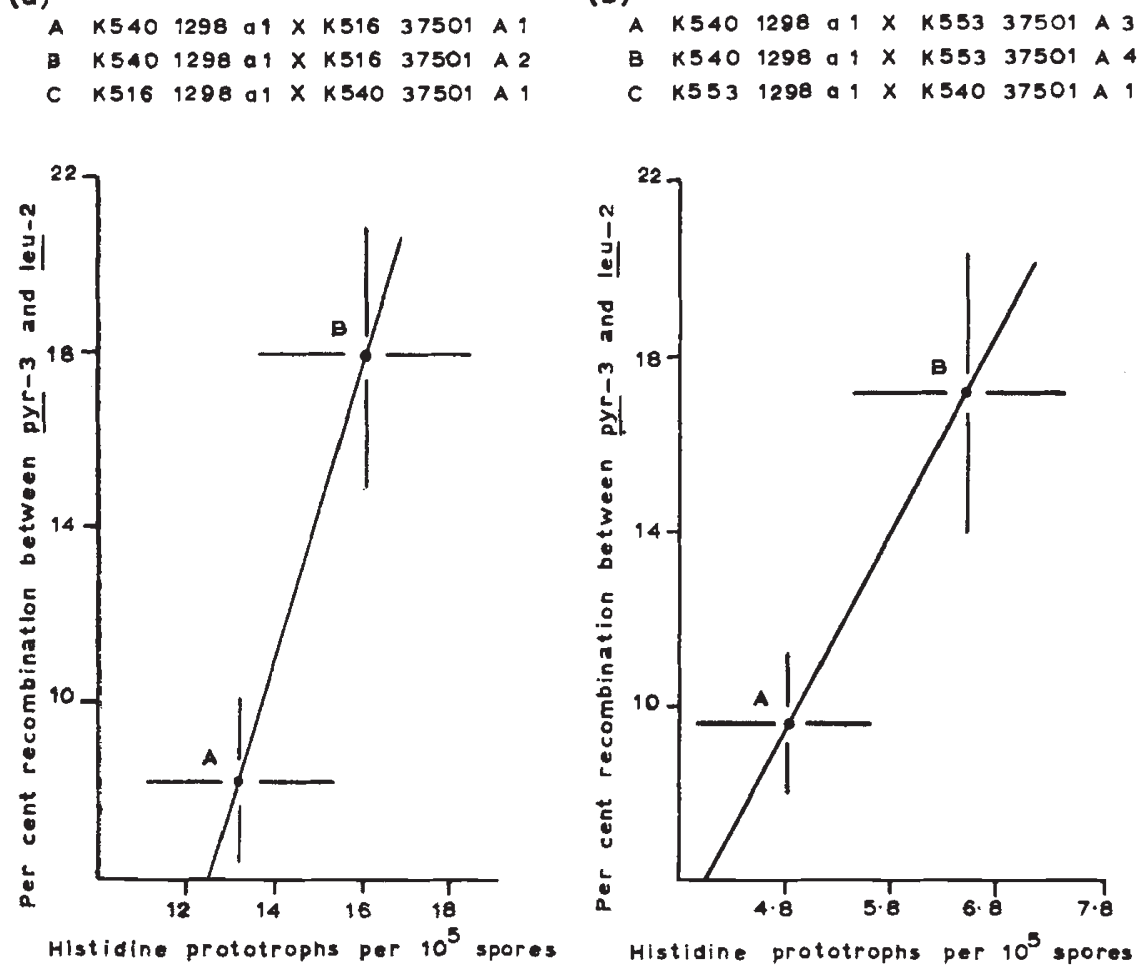

(c)

(d)

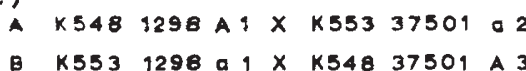

A K553 1298 a1 X K516 37501 A2
B K553 129B a 1 X K516 37509 A

FIG. 2.-The frequency of histidine prototroph formation plotted against the frequency of recombination between flanking markers for four sets of crosses between pairs of his-5 alleles that are reciprocally or independently marked. 
of histidine prototroph formation plotted against the frequency of recombination between flanking markers for crosses of the four types $\mathrm{K}_{540} \times \mathrm{K}_{51} 6, \mathrm{~K}_{540} \times \mathrm{K}_{553}, \mathrm{~K}_{54}{ }^{8} \times \mathrm{K}_{553}$ and $\mathrm{K}_{553} \times \mathrm{K}_{51} 6$. In the crosses between $\mathrm{K}_{540}$ and $\mathrm{K}_{5} \mathrm{I} 6$ and $\mathrm{K}_{540}$ and $\mathrm{K}_{553}$, fig. $\mathrm{I} a$ and $\mathrm{I} b$ respectively, the increases in frequency of allelic recombination are directly proportional to the increases in frequency of recombination between flanking markers. In the crosses between $\mathrm{K}_{548}$ and $\mathrm{K}_{553}$ and $\mathrm{K}_{553}$ and $\mathrm{K}_{516} 6$, fig. $\mathrm{I} c$ and $\mathrm{I} d$ respectively, increases in the frequency of allelic recombination are accompanied by proportionally much larger increases in frequency of recombination between the flanking markers and the probability of the increases being proportional is less than $0.0 \mathrm{I}$ in each case.

(ii) Mapping by prototroph frequencies. A map of the fine structure of the his- 5 gene based on the frequency of prototroph formation in crosses between pairs of his-5 alleles is shown in fig. 3. Where more than one value was obtained for the frequency of allelic recombination between a pair of alleles, the frequency shown is the weighted mean. The significant variation in frequency of prototroph formation already noted indicates that considerable caution is necessary in constructing the map. However, even when the alternative values for prototroph frequencies are substituted in the map, the order of the sites of difference between the alleles inferred from the data does not change.

In the reciprocally marked crosses between $\mathrm{K}_{7} 8$ and $\mathrm{K}_{155}$ no prototrophs were observed in a total of $64 \times 10^{5}$ viable ascospores. This might be thought to indicate that the two alleles are the result of changes at the same site in the genetic material. Unfortunately, the two mutants were both isolated in the same experiment, an examination of which reveals the distinct possibility that these mutants are tivo isolates of the same original colony.

Two crosses are outstanding for their unexpectedly low frequency of prototroph formation. These two are the crosses $\mathrm{K}_{550} \times \mathrm{K}_{542}$ and $\mathrm{K}_{550} \times \mathrm{K}_{729}$ which gave frequencies of $0 . \mathrm{I}^{\mathrm{I}}$ per $\mathrm{IO}^{5}$ and 0.09 per $10^{5}$ spores respectively whereas the expected values were in the region of 20 per $10^{5}$. The frequencies in these crosses are so low that they might be the result of reversion of on $\epsilon$ of their component stocks. Indeed the self cross $\mathrm{K}_{55^{\circ}} \times \mathrm{K}_{55^{\circ}}$ did indicate a higher frequency of reversion than is usual for other selfed his- 5 mutants. Further information on the reversion frequency of $\mathrm{K}_{550}$ and several other his-5 mutants was obtained by plating large numbers of conidia in Vogel's medium and counting the histidine prototrophs that occurred. The results of these tests are shown in table 5. It is apparent that the frequency of $\mathrm{K}_{550}$ is of the order of twenty times that of the other four his-5 mutants tested. The frequency of reversion amongst conidia of $\mathrm{K}_{550}$, I in $4 \times 10^{6}$ conidia, although not directly comparable to the frequency of reversion in ascospores, indicates that an appreciable number of the histidine prototrophs found in the two crosses $\mathrm{K}_{550}$ $\times \mathrm{K}_{542}$ and $\mathrm{K}_{550} \times \mathrm{K}_{729}$ could be the result of reversions of the 


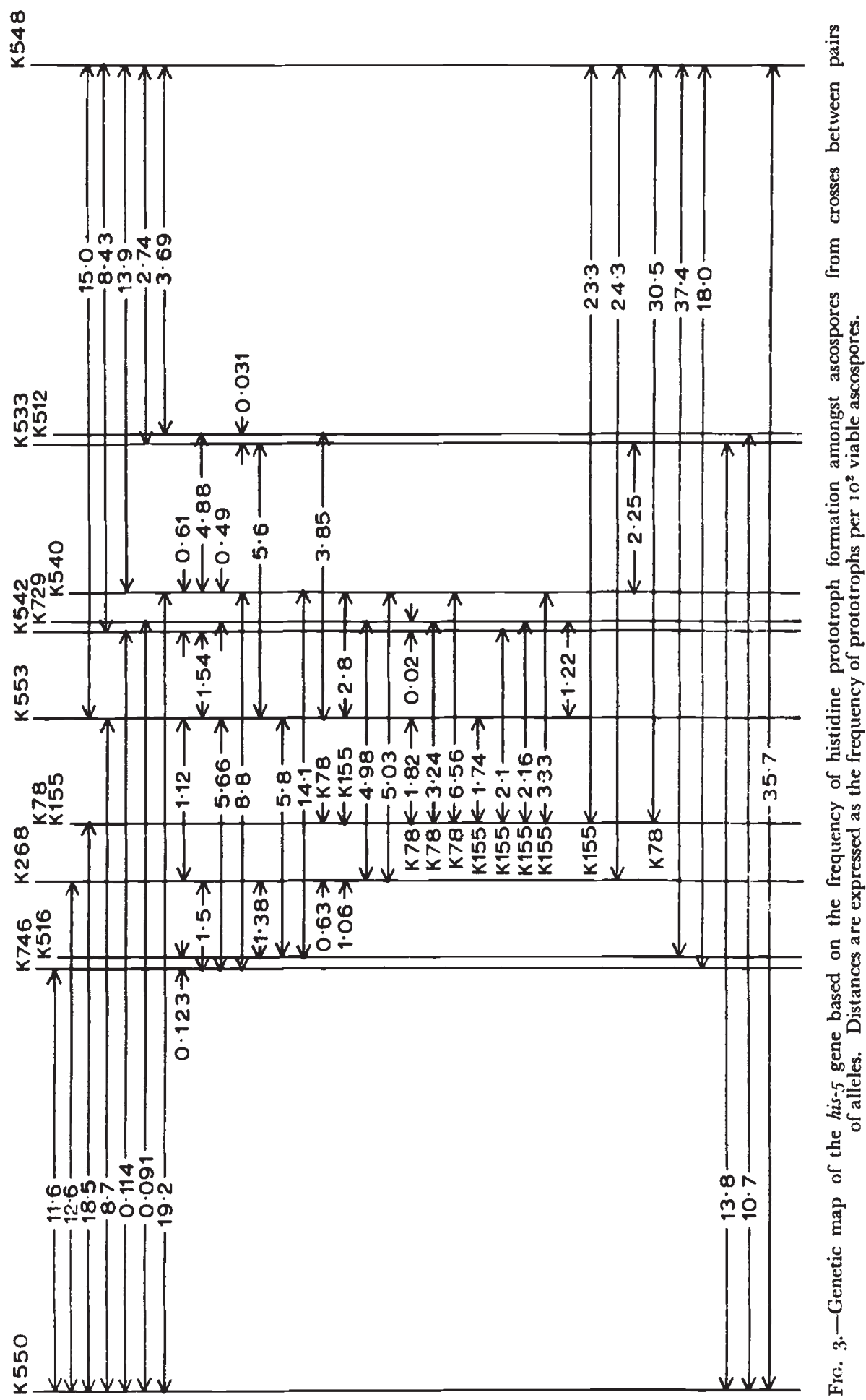


$\mathrm{K}_{550}$ component. Thus it is quite possible that the rate of recombination between these pairs of alleles is considerably lower than the frequency of prototroph formation indicates. As yet no satisfactory explanation of these anomalous frequencies can be made.

(iii) The additivity of prototroph frequencies. It may be seen from the genetic map, fig. 3 , that it is often found that the frequency of prototroph formation between a pair of alleles considerably exceeds the sum of the individual values for the intervals between the pair. It is convenient here to introduce the term map distance which may be defined as the sum of the individual frequencies of recombination between successive adjacent sites in the genetic map. If the additivity

TABLE 5

Spontaneous reversion to prototrophy amongst conidia

\begin{tabular}{|c|c|c|c|c|c|}
\hline \multirow{2}{*}{$\begin{array}{l}\text { His }-5 \text { allele } \\
\text { tested }\end{array}$} & \multirow{2}{*}{$\begin{array}{l}\text { Number of } \\
\text { viable conidia } \\
\text { in millions }\end{array}$} & \multirow{2}{*}{$\begin{array}{l}\text { Number of } \\
\text { reversions }\end{array}$} & \multirow{2}{*}{$\begin{array}{l}\text { Frequency of } \\
\text { reversion per } \\
10^{8} \text { conidia }\end{array}$} & \multicolumn{2}{|c|}{$\begin{array}{l}\text { Limits to the frequency of } \\
\text { reversion per } 10^{8} \text { conidia } \\
\text { when } P=0.05\end{array}$} \\
\hline & & & & Lower limit & Upper limit \\
\hline $\begin{array}{l}\mathbf{K}_{550} \\
\mathbf{K}_{516} \\
\mathbf{K}_{540} \\
\mathbf{K}_{553} \\
\mathbf{K}_{729}\end{array}$ & $\begin{array}{r}21 \cdot 7 \\
127 \cdot 8 \\
258 \cdot 3 \\
333.8 \\
234.6\end{array}$ & $\begin{array}{l}5 \\
1 \\
4 \\
3 \\
3\end{array}$ & $\begin{array}{c}23 \cdot 0 \\
0.78 \\
1 \cdot 55 \\
0.899 \\
1 \cdot 23\end{array}$ & $\begin{array}{l}7.47 \\
0.198 \\
0.422 \\
0.185 \\
0.264\end{array}$ & $\begin{array}{c}53 \cdot 8 \\
4 \cdot 36 \\
3 \cdot 96 \\
2 \cdot 63 \\
3 \cdot 74\end{array}$ \\
\hline
\end{tabular}

rule as previously stated (p. 257) holds then the frequency of recombination between any pair of alleles should equal the map distance between them. Fig. 4 shows the frequency of recombination plotted against the map distance for each cross. It is apparent that the data generally indicate that the frequency of recombination exceeds the map distance and that the higher the recombination frequency the more it exceeds the map distance. This phenomenon is termed map expansion. Although the majority of the data indicates a considerable degree of map expansion there is a group of crosses that is exceptional in exhibiting a low degree of map expansion or in some cases a degree of map contraction. Almost all of these crosses have one parental component in common this being the his-5 allele $\mathrm{K}_{55}$. In fig. 4 all crosses in which one parental strain contains $\mathrm{K}_{550}$ are distinctively marked with circles.

\section{(b) Distribution of flanking markers}

The distribution of the flanking markers pyr-3 and leu-2 amongst histidine prototrophs is shown in table 2 which also shows the order of the his-5 allele differences as inferred according to the three criteria already explained (p. 3). The orders are expressed in terms of the 
proximal allele difference. For each cross where more than ten prototrophs are concerned in the comparison made, an indication is given of the statistical reliability of the orders. Those significant at

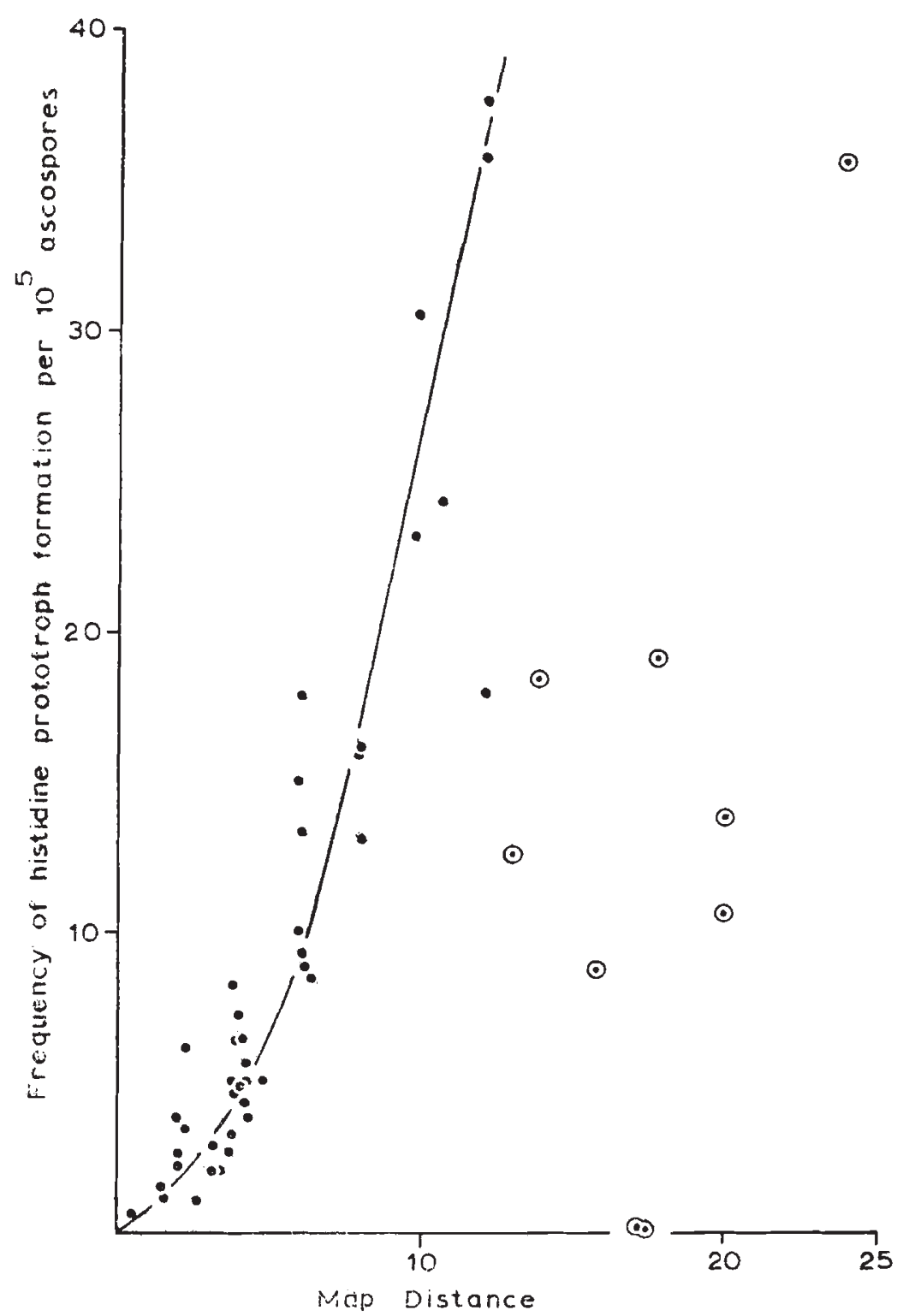

FIG. 4.-The frequency of histidine prototroph formation in crosses between pairs of his-5 itlieles plotted against the map distance between them. Results of crosses in which one parental strain contains $\mathrm{K}_{55}$ are marked with circles.

the 5 per cent. level $(\mathrm{P}=0.05$ or less) are shown in bold type, while those with a $\mathrm{P}$ value between 0.05 and 0.3 are shown in italics. Standard type is used for those with a $\mathrm{P}$ value of 0.3 or greater and also where less than ten prototrophs are concerned in the comparison. 

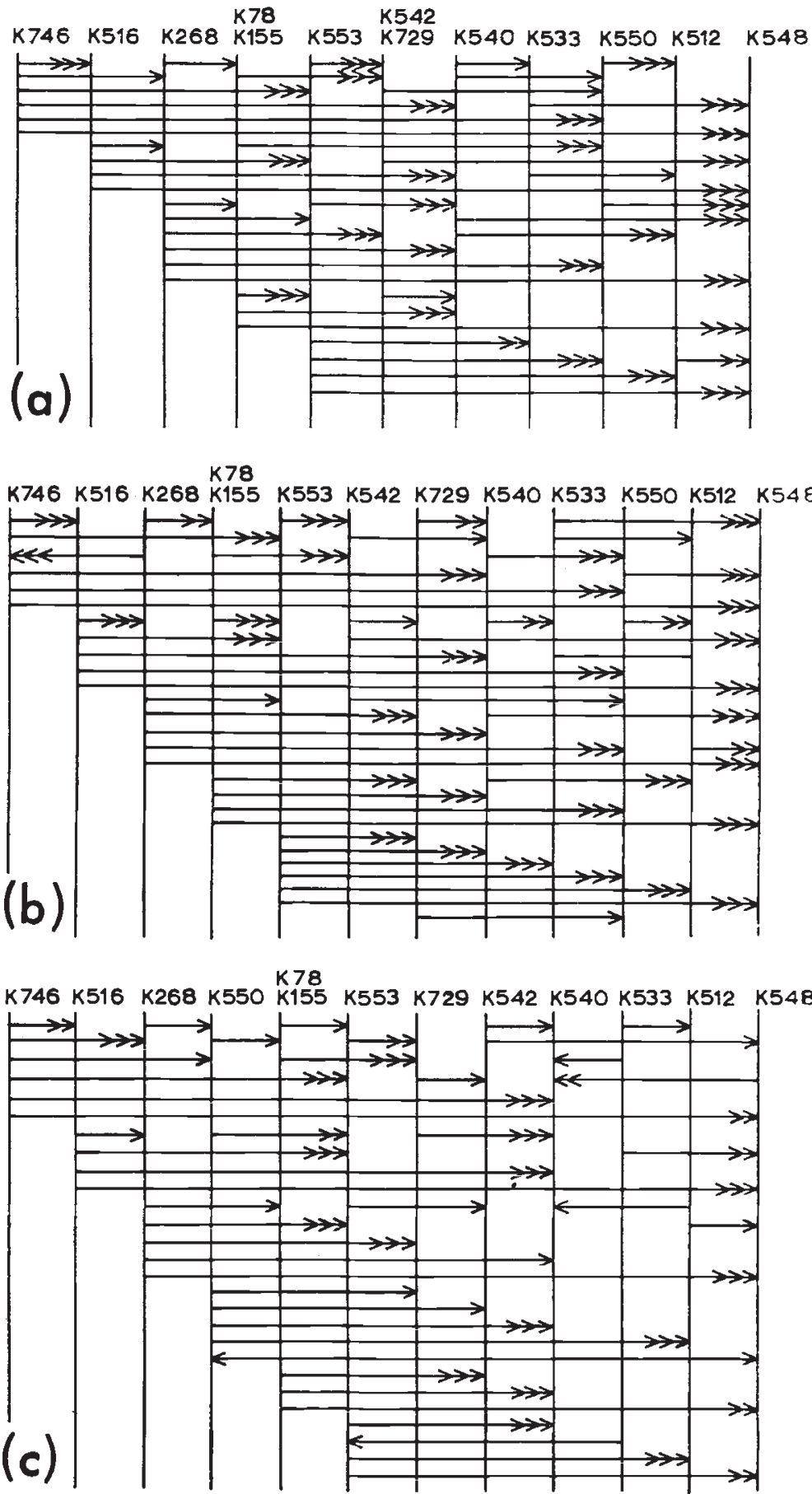

Fig. 5.-The order of the allele differences deduced from the distribution of flanking markers amongst the prototrophic recombinants formed in crosses between pairs of his -5 alleles. Each horizontal line represents a cross and the arrowheads indicate the distal allele. (a) The best order obtained using criterion I. (b) The best order obtained using criterion II. (c) The best order obtained using criterion III. 
As a whole, these data indicate an order of the allele differences (fig. 5) which is consistent with the order derived from comparison of prototroph frequencies (fig. 3). The consistency of the orders derived from considering the distribution of the flanking markers is most readily grasped by plotting the data by means of lines joining the positions of the allele differences, the distal position being marked by an arrow. In fig. 5, the orders significant at the 5 per cent. level are indicated by threc arrows. Those orders where $\mathrm{P}$ is between 0.05 and 0.3 are indicated by two arrows and those where $\mathrm{P}$ exceeds 0.3 are indicated by a single arrow. Criteria I and II give a high degree of consistency; criterion III being somewhat less consistent. There is one notable exception to the consistency of the order of allele differences inferied by the three criteria and once again this concerns the his-5 mutant $\mathrm{K}_{550}$. Criteria $\mathrm{I}$ and II both indicate that $\mathrm{K}_{550}$ is between $\mathrm{K}_{533}$ and $\mathrm{K}_{512}$ towards the distal end of the gene. This disagrecs with its location at the opposite end of the gene in the genetic map. Criterion III differs from the other two criteria in locating $\mathrm{K}_{550}$ between $\mathrm{K}_{2} 68$ and $\mathrm{K}_{7} 8$ towards the proximal end of the gene. The location of $\mathrm{K}_{550}$ by criterion III is not significantly different from its location in the genetic map based on prototroph frequencies.

\section{RELATION BETWEEN GENETIC AND COMPLEMENTATION MAPS}

Ninety his-5 mutants were tested, in all possible pairwise combinations, for their ability to complement one another. Fifty-eight of the niutants had been tested for complementation previously (Catcheside, I960). With one exception the results for these mutants are identical to those previously reported. However, complementation could not be demonstrated between the alleles $\mathrm{K}_{5} \mathrm{I} 6$, complementation group $\mathrm{B}$ of Ciatcheside, and $\mathrm{K}_{54} \mathrm{I}$, group $\mathrm{F}$, as was previously reported (Catcheside, I960). Neither did $\mathrm{K}_{5} \mathrm{I} 6$ complement other new group $\mathrm{F}$ mutants. The combination $\mathrm{K}_{5} \mathrm{I} 6+\mathrm{K}_{54} \mathrm{I}$ was further studied by combining the methionine- 3 mutant 36 Io4 with $K_{5}$ I6 and the leu-2 mutant 375 or with $\mathrm{K}_{54}$ I so that a forced heterocaryon cultured on minimal medium supplemented with histidine, could be prepared. In turn the heterocaryon was tested for its ability to grow on minimal medium, with the finding that it was unable to grow on this medium. It must be concluded that $\mathrm{K}_{5} \mathrm{I} 6$ does not complement $\mathrm{K}_{54} \mathrm{I}$, and the apparent complementation between them observed by Catcheside, probably resulted from a reversion of one of the two mutants. $\mathrm{K}_{746}$, previously the sole member of group $\mathrm{C}$, has now been included with $\mathrm{K}_{5} \mathrm{I} 6$ in group $\mathrm{B}$ since these two mutants exhibit the same complementation characteristics.

Of the 32 his- 5 mutants not previously tested for complementation only one, K877, exhibited a new complementation pattern. K877, now designated group $\mathrm{C}$, complements only groups $\mathrm{F}$ and $\mathrm{G}$ mutants, a complementation pattern which fills a gap in the complementation 
map, and which orders the groups more definitely in the complementation map. The ninety his-5 mutants are listed in table I in their complementation groups, and the complementation pattern of the mutants has been interpreted in terms of a linear complementation map (fig. 6).

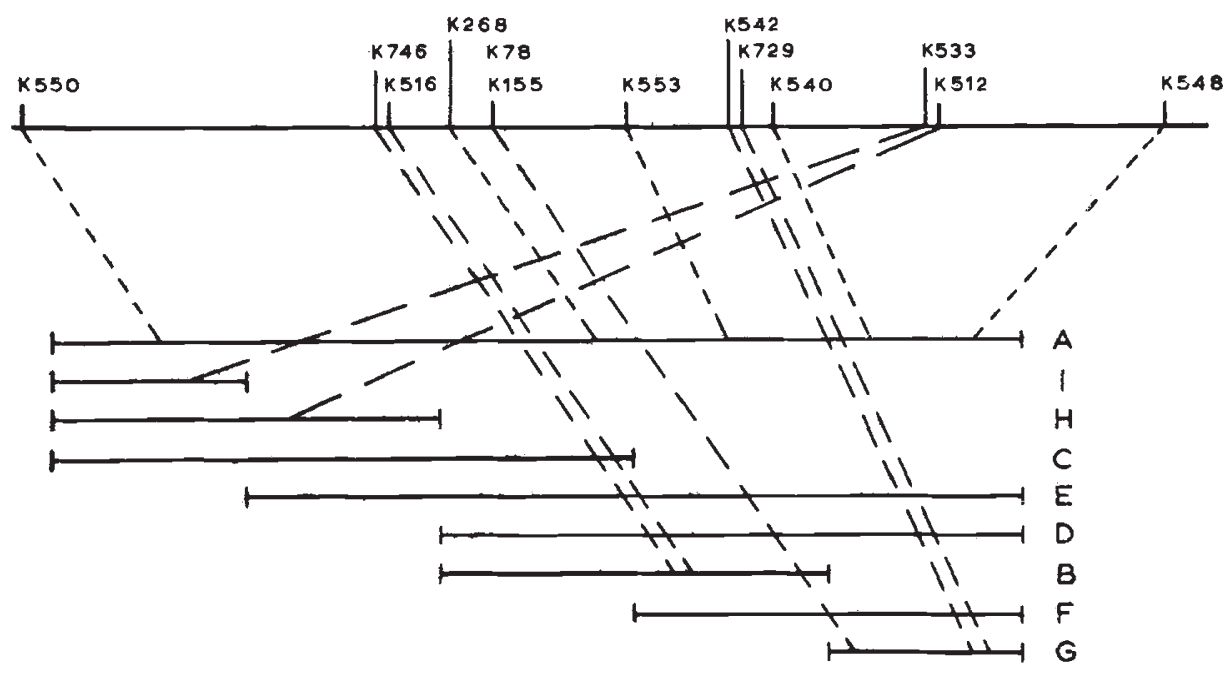

Fig. 6.-Comparison of genetic and complementation maps. Note that the two maps are not colinear.

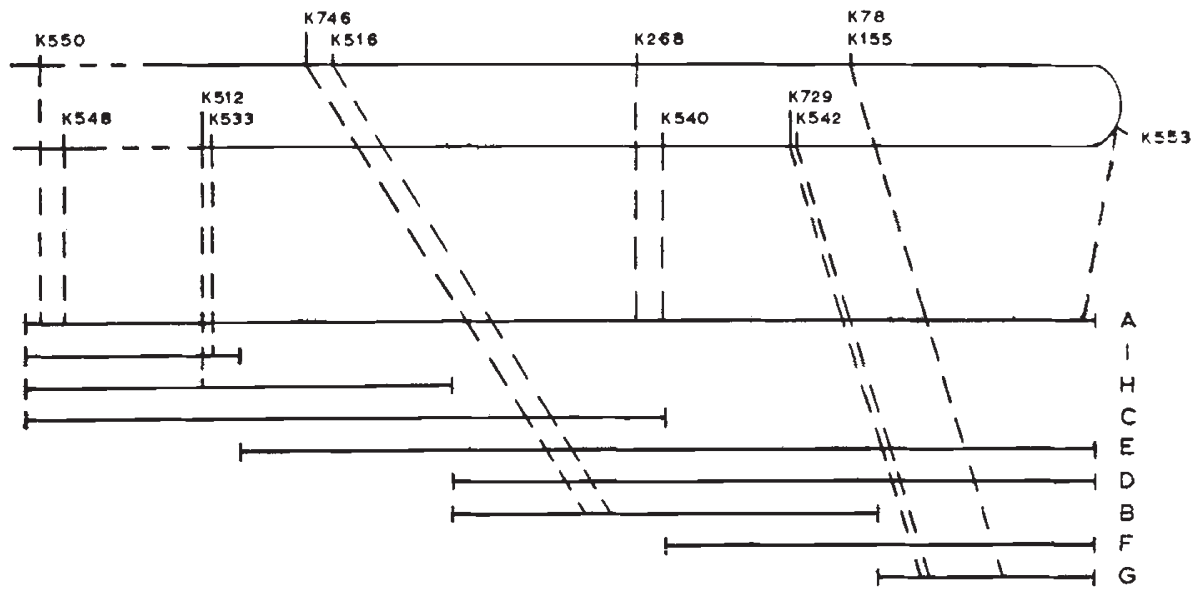

FIG. 7.-Comparison of genetic and complementation maps. The order of the allele differences in the folded genetic map mimics the order of their complementation groups in the complementation map.

We are now in a position to compare the genetic and complementation maps. In fig. 6 it will be seen that the non-complementing mutants are scattered throughout the genetic map. The four group $\mathrm{G}$ mutants occur in two pairs which are separated by only a single group A mutant. The two group B mutants are closely linked proximally 
to the group $G$ mutants and the $H$ and $I$ mutants are closely linked and distal to the group $G$ mutants. Thus it is clear that the two maps are not colinear. Onc way in which the order of the mutants in the genctic map can be made to mimic the order of their complementation groups in the complementation map is by folding the genetic map back on itself as shown in fig. 7. It should be noted that in order to preserve the scalc of the genetic map the fold must be between the two pairs of group $G$ mutants. Since it may be that the relation between the genetic and complementation maps reflects in some way the structure of the enzyme produced, it will be of great interest to see if the location of further complementing mutants in the genetic map supports the relation demonstrated so far.

\section{DISCUSSION}

The main purpose of the study of recombination between his-5 mutants was to construct a genetic map to show the relative positions of the allelic differences, and to compare this with the complementation map. Since it has been demonstrated in other genes that complcmentation occurs at the protein level (Woodward, 1959; Fincham and Coddington, 1963 ) it is not unreasonable to assume that the position in the genetic map of the sites of difference of mutants of each complementation group may reflect in some way the structure and geometry of the enzyme produced. In the his-5 gene the non-complementing mutants appear to be scattered throughout the length of the genetic map. This is also the case in pan-2 (Case and Giles, 1958) and $m e-2$ (Murray, 1960, 1963) and seems to be the more usual arrangement, although in his-I (Jessop and Catcheside, unpub.) the non-complementing mutants are all concentrated at the proximal end of the map. His-5 mutants of each complementation group appear to be grouped together in the genetic map although not in the same linear order as in the complementation map. However, since only a few complementing his- 5 alleles have been located in the genetic map the exact relation between the maps is not yer clear. Nevertheless, it is certain that the two maps are not entirely colinear.

The distribution of the flanking markers amongst prototrophic recombinants appears to provide a reliable indication of the order of the sites of difference in the his-5 gene. Three criteria (Catcheside, Jessop and Smith, 1964) based on the distribution of the markers amongst the prototrophs of each cross when applied to the data systematically indicate, with remarkable consistency, an order for the sites of difference that agrees with their order in the genetic map based on the frequency of prototroph formation. These same criteria when applied to the me-2 (Murray, I96o, I963), pan-2 (Case and Giles, 1958) and his-I data (Jessop and Catcheside, r965) all indicate with reasonable consistency, orders for the sites of difference that are the same as those based on the frequency of prototroph formation. In other data the asymmetries of marker distribution are not always so 
sharp but are usually shown to some extent by one of the flanking markers.

A reliable method of ordering allelic differences would be provided by mapping topologically, using a set of overlapping deficiencies. A topological map of the his- 5 gene may be expected to indicate the same order of the allelic differences as is indicated by the criteria already used. Efforts are now being made to induce and select structural mutants that may be suitable for constructing a topological map.

The only his-5 allele that does not appear to behave as a point mutation is $\mathrm{K}_{55^{\circ}}$. In the genetic map based on prototroph frequencies $\mathrm{K}_{55} \mathrm{O}$ appears to be located at the proximal end of the map. However, two of the flanking marker criteria, criteria $I$ and II, indicate a position towards the distal end of the map. In addition, when $\mathrm{K}_{550}$ was crossed with two alleles located in the centre of the map unexpectedly low frequencies of prototrophs were found. It seems possible that $\mathrm{K}_{55} \mathrm{O}$ is a structural mutation of some complexity although it cannot be a deletion since it has the highest reversion rate of all the his- 5 alleles tested. The high reversion rate of $\mathrm{K}_{550}$ also seems to indicate that it is not a double mutant. Nevertheless, a second mutant site located close to $\mathrm{K}_{542}$ and $\mathrm{K}_{729}$ would explain the low rates of recombination observed in crosses between $\mathrm{K}_{55} \mathrm{O}$ and these alleles. Even so it is difficult to see why low rates of recombination are not also shown in crosses between $\mathrm{K}_{55}$ and other alleles that are closely linked to $\mathrm{K}_{542}$ and $\mathrm{K}_{729}$. It is hoped that topological mapping will provide a more certain indication of the nature and location of this anomalous allele.

The differences in prototroph formation observed in certain crosses between the same pairs of his- 5 alleles that are reciprocally or independently marked are particularly interesting. An understanding of recombination at the molecular level is of fundamental importance but it is only recently that theories have been proposed which take account of the molecular structure of deoxyribonucleic acid and of its time of replication with respect to the time of genetic recombination at meiosis (Holliday, 1962, 1964; Whitehouse, 1963; Hastings and Whitehouse, 1964). These proposals include, variously, separation over a short distance of the two chains of a DNA molecule, the breakage of one or both of these separated chains, the formation of segments of DNA of hybrid origin, the excision of mispaired bases or segments of a DNA chain, and the reconstruction of segments of the DNA chain using information in the other chain. Many of these events would involve chemical reactions. It is a characteristic of organisms that such reactions are catalysed by enzymes and that each enzyme is structurally specified by a gene which may be controlled either directly or indirectly by other genes. It must be in these terms that the differences in frequency of recombination between various his-5 stocks must be interpreted.

The most plausible suggestion that can be made is that the difference 
in recombination frequencies is the result of some effect on the breakage process. Variation in the efficiency of an enzyme whose function is to produce breaks in DNA molecules would bring about variation in the frequency of the breaks and thus vary the number of occurrences of subsequent events that may lead to recombination. This would be a mechanism which would be expected to change the frequency of recombination without necessarily altering the distribution of the flanking markers amongst the prototrophic recombinants. In the cases observed, changes in frequency of recombination do not appear to be correlated with any changes in the distribution of the flanking markers. If recombination between alleles and non-alleles is by the same process then an increase in the effectiveness of an enzyme producing breaks should be coupled with proportional increases in allelic and non-allelic recombination as was found in the his-5 data. It will also be appreciated that variations in efficiency of an enzyme producing breaks should affect allelic recombination at all loci and not just a single locus. However, adequate test of this may be frustrated by the considerable technical difficulty of measuring the relatively small differences in the frequency of recombination that are observed in the his-5 data. If it is assumed that the higher frequencies observed in the his-5 data are the result of an enzyme which is more efficient in producing breaks then it may be expected that the high frequency form will be dominant to the low frequency form. Since it seems probable that the differences in frequency observed are genetically controlled efforts are being made to test this prediction.

The remarkable feature of recombination data from various fungi is the great variability affecting all aspects of recombination which exists not only between different species, but also between genes in the same species and even between the same pairs of alleles. In the past, interest has been concentrated on fine structure mapping and on the nature of "conversion". In these respects, the variability observed has been regarded as more of a nuisance than a possible source of information about mechanisms (Catcheside, Jessop and Smith, 1964). It appears that close study of the nature and origin of genetic and other variations that affect recombination is essential to any complete understanding of the molecular processes that produce genetic recombination.

Acknowledgments.-The author wishes to express his grateful thanks to Professor D. G. Catcheside, F.R.S., for his encouragement and for much valuable discussion given throughout these investigations. Thanks are also due to $\mathrm{Mr} \mathrm{R}$. Haddock and Miss Anne Todd for technical assistance.

\section{REFERENCES}

AMES, B. N., AND HORECKER, B. L. 1956. The biosynthesis of histidine; Imidazole acetol phosphate transaminase. F. Biol. Chem., 220, I1 3-1 28.

CASE, MARY E., AND GILES, N. H. 1958. Recombination mechanisms at the pan-2 locus in Neurospora crassa. Cold Spring Harb. Symp. Quant. Biol., 23, I 19-1 35. 
CAtCheside, D. G. I96o. Complementation among histidine mutants of Neurospora crassa. Proc. Roy. Soc. Lond., BI53, 179 -194.

CATCheside, D. G., JEsSOP, ADRIENNE P., AND SMITh, B. R. 1964. Genetic controls of allelic recombination in Neurospora. Nature, 202, 1242-1 243.

FINGHAM, J. R. S., AND CoDdington, A. I963. Complementation at the am locus of Neurospora crassa: a reaction between different mutant forms of glutamate dehydrogenase. 7. Mol. Biol., 6, 36I-373.

Holliday, R. 1962. Mutation and replication in Ustilago maydis. Genet. Res., 3, $472-486$.

Holliday, R. 1964. A mechanism for gene conversion in fungi. Genet. Res., 5, 282-303.

JESSOP, ADRIENNE P., AND CATChESIDE, D. G. 1965. Interallelic recombination at the his-I locus in Neurospora rrassa and its genetic control. Heredity, 20, $237 * 256$.

SIURRAY, NOREEN E. 1960. Complementation and recombination between methionine-2 alleles in Neurospora crassa. Heredity, 15, 207-2 I 7.

MURRAY, NOREEN E. I963. Polarised recombination and fine structure within the me-2 gene of Neurospora crassa. Genetics, 48, I $163-1$ I 83.

NEWMEYER, DOROTHY. 1954. A plating method for genetic analysis in Neurospora. Genetics, 39, 604-618.

Sмiтн, B. R. 1962. Linkage data for group IV. Neurospora Newsletter, 1, 16-17.

vogel, H. J. 1955. A convenient growth medium for Neurospora. Microbial Genet. Bull., 13, 42 .

WestergaARD, M., AND MITChell, H. K. 1947. Neurospora V. A synthetic medium favouring sexual reproduction. Amer. F. Bot., 34, 573-577.

WHITEHOUSE, H. L. K. 1963. A theory of crossing over by means of hybrid deoxyribonucleic acid. Nature, 199, 1034-1040.

Whitehouse, H. L. K., AND hastings, P. J. 1965. The analysis of genetic recombination on the polaron hybrid DNA model. Genet. Res. (in press).

WOODWARD, D. O. 1959. Enzyme complementation in vitro between adenylosuccinaseless mutants of Neurospora crassa. Proc. nat. Acad. Sci., Wash., 45, 846 . 